\title{
Fire cue effects on seed germination of six species of northwestern Patagonian grasslands
}

\author{
S. L. Gonzalez and L. Ghermandi \\ Laboratorio Ecotono, Instituto Nacional de Investigaciones en Biodiversidad y Medioambiente, \\ CONICET-Universidad Nacional del Comahue, Quintral 1250 (8400), Bariloche, Argentina
}

Correspondence to: S. L. Gonzalez (solau.gonzalez@gmail.com)

Received: 10 November 2010 - Accepted: 18 December 2010 - Published: 6 September 2012

\begin{abstract}
Postfire recruitment of seedlings has been attributed to a stimulation of germination by fire-related cues. The germination response to heat shock $\left(80^{\circ} \mathrm{C}-5 \mathrm{~min}\right)$, smoke $(60 \mathrm{~min})$, the combination of both factors and no heat no smoke (control) was studied in six native species (two dominant grasses, two dominant shrubs and two annual fugitive herbs) of northwestern Patagonian grasslands. Seeds of the grasses Festuca pallescens and Stipa speciosa and the shrub Senecio bracteolatus (Asteraceae) germinated when they were exposed to heat shock, whereas seeds of the other shrub, Mulinum spinosum (Apiaceae), were killed by this fire cue. In grasses, probably the glume of caryopsis protected embryos from heat. Possibly, the seed size could explain the different responses of the two shrubs. Heat combined with smoke reduced seed germination for $S$. speciosa and $S$. bracteolatus. The heat could have scarified seeds and the longer exposure to smoke could have been toxic for embryos. The same treatment increased germination of the annual fugitive herb Boopis gracilis (Calyceraceae). We concluded that fire differentially affects the seedling recruitment of the studied species in the northwestern Patagonian grasslands.
\end{abstract}

\section{Introduction}

In fire-prone ecosystems, many plants have developed regeneration mechanisms which allow them to survive fire and persist in time (Whelan, 1995). Resprouting plants replace the biomass removed by fire from surviving aboveor below-ground dormant meristems, whereas non-sprouting species are killed by fire and depend on seed for persistence (Bond and van Wilgen, 1996). In the first postfire growing season, massive seedling recruitment of seeder shrubs and fugitive species from the soil seed bank is commonly observed (Ghermandi et al., 2004; Keeley et al., 2005). The latter species occupy the site temporarily and their abundance normally decreases in subsequent years. Stimulation of germination has been attributed to fire-related cues, principally heat and smoke, which can break seed dormancy and promote germination (Keeley and Fotheringham, 2000).

Fire-related cues can trigger seed germination when applied singly or in combination (Morris, 2000; Gilmour et al., 2000). However, some studies from chaparral and tropical savannas showed that the combination of heat shock and plant-derived smoke can produce a decrease in germination (Keeley and Fotheringham, 1998; Williams et al., 2003). Heat and smoke applied individually can also reduce or inhibit seed germination, especially when seeds are exposed to excessive intensity or prolonged periods of heat or high concentration of smoke (Dixon et al., 1995; Pennacchio et al., 2007). Seeds in the soil experience a combination of several cues during and after fire, but their germination response to the combination of heat shock and smoke is not well understood (Thomas et al., 2007).

Northwestern Patagonian grasslands are structured by a tussock grasses matrix and sparse shrubs. The relative abundance of these functional groups is changed by largescale disturbances like fire and livestock grazing (Boelcke, 1957). Fires normally occur during dry summers and the burned areas can be extensive because dominant vegetation accumulates large amounts of fast-drying fuel and their spatial continuity favors fire spread (de Torres Curth et al., 2008). However, these grasslands are resilient because of the fast regrowth of grasses and shrubs and seedling recruitment from the seed bank (Ghermandi et al., 2004). Fire is often caused by lightning; however fire occurrence of anthropogenic origin has increased in recent years (de Torres Curth et al., 2008). Since climate changes and anthropogenic 
effects influence fire regimes, postfire seedling recruitment could be affected by these changes as well. However, studies carried out about how seeds respond to fire in these grasslands are scarce (Franzese and Ghermandi, 2011).

Our study focused on native dominant grasses and shrubs and also on annual fugitive herbs. We studied perennial grasses and shrubs which predominantly resprout after fires and their seeds do not accumulate a seed bank (Gonzalez and Ghermandi, 2008). We have no records of postfire massive germination of species of these two functional groups. Another postfire phenomenon in these grasslands is the massive seedling recruitment of annual fugitive herbs from the soil seed bank (Gonzalez and Ghermandi, 2008). Occasionally these species may germinate with other intense disturbances, such as soil removal. Based on these observations we hypothesized that: (a) heat and smoke have a neutral or negative effect on seed germination of grasses and shrubs; and that (b) fire related cues stimulate the seed germination of annual fugitive herbs. We investigated whether heat and smoke and the combination of both factors trigger seed germination of some species of grasses, shrubs and annual herbs and whether seeds of these species tolerate heat shock. The species studied are part of characteristic functional groups in most grasslands and this study aims to contribute to the knowledge of the fire ecology of these systems.

\section{Methods}

\subsection{Study species, seed collection and storage}

We selected six native species of the northwestern Patagonian grasslands: two dominant grasses; Festuca pallescens (Poaceae) and Stipa speciosa (Poaceae), two dominant shrubs; Senecio bracteolatus (Asteraceae), Mulinum spinosum (Apiaceae), and two annual herbs; Boopis gracilis (Calyceraceae) and Nicotiana linearis (Solanaceae). B. gracilis and $N$. linearis are fugitive herbs, which recruit in great abundance after fires but drastically reduce their cover one year later (Ghermandi et al., 2004).

Seeds were collected in February-March 2008 in grasslands at San Ramón Ranch, $\left(41^{\circ} 03^{\prime} 19^{\prime \prime} \mathrm{S}\right.$ and $\left.71^{\circ} 01^{\prime} 50^{\prime \prime} \mathrm{W}\right)$, $30 \mathrm{~km}$ east of San Carlos de Bariloche, Argentina. Seeds were stored under laboratory conditions $\left(20-25^{\circ} \mathrm{C}\right)$ for one or two months until used in germination treatments. Visibly damaged seeds were discarded.

\subsection{Heat and smoke treatments}

Seeds of all species were exposed to four treatments: heat $\left(80^{\circ} \mathrm{C}\right)$, smoke, heat combined with smoke, and control (no heat and smoke). Five replicates of 20 seeds were used for each treatment. The heat treatment was performed by placing seeds in a drying oven at $80^{\circ} \mathrm{C}$ for five minutes. The selected temperature was within the range of below-ground temperatures registered at $1 \mathrm{~cm}$ deep during experimental grassland fires (J. Franzese, unpublished data).

The smoke treatment followed the methodology of Dixon et al. (1995). Samples were placed into a plastic tent and exposed to smoke for $60 \mathrm{~min}$. To generate smoke, a mixture of fresh and dry plant material of dominant grasses (Festuca pallescens, Stipa speciosa) and shrubs (Mulinum spinosum, Senecio bracteolatus, Acaena splendens) were collected from grassland and burned in a drum. In the cases of combined treatments, heat was applied before smoke and no more than one hour elapsed between the two treatments.

\subsection{Germination trials}

After treatments, seeds were placed over two sheets of filter paper, inside 9-cm diameter Petri dishes and moistened with distilled water. To prevent mold contamination, seeds were sterilised with 5\% sodium hypochlorite for 3-4 min prior to treatments, washed three times with distilled water and dried at ambient temperature. After treatments, all replicates were treated with a fungicide solution (Valbuena and Vera, 2002). The petri dishes were sealed with parafilm to reduce desiccation. Seeds of all species were incubated in a germination chamber under controlled temperature and photoperiod: $13 \mathrm{~h}$ light $\left(18^{\circ} \mathrm{C}\right) / 11 \mathrm{~h}$ dark $\left(5^{\circ} \mathrm{C}\right)$. The study lasted 13 weeks and the germinated seeds were counted and removed every week. The protrusion of the radicle was the criterion for germination. The viability of ungerminated seeds was tested with the application of $0.1 \%$ solution of 2,3,5-triphenyl tetrazolium chloride which stains living embryos red (Baskin and Baskin, 1998).

\subsection{Statistical analyses}

The percentage of seed viability was calculated and the seeds were classified as germinated, dormant (non-germinated but viable) and dead. The statistical analysis of the percentage of seed germination and seed viability for each species among treatments was carried out with one-way ANOVA. The Tukey's test was used for a posteriori comparison of the means.

\section{Results}

\subsection{Seed germination}

Fire-related cues did not affect seed germination of the grasses $(P>0.05)$ (Fig. 1a and b), although the germination of Stipa speciosa was somewhat lower when seeds were exposed to Heat + Smoke treatment (Fig. 1b). Senecio bracteolatus seeds showed that decrease of the germination for the combined treatment was significant $(P<0.05)$ (Fig. 1c). Seeds of Mulinum spinosum had a low percentage of germination both in Control and Smoke treatments and did not germinate when they were exposed to Heat 

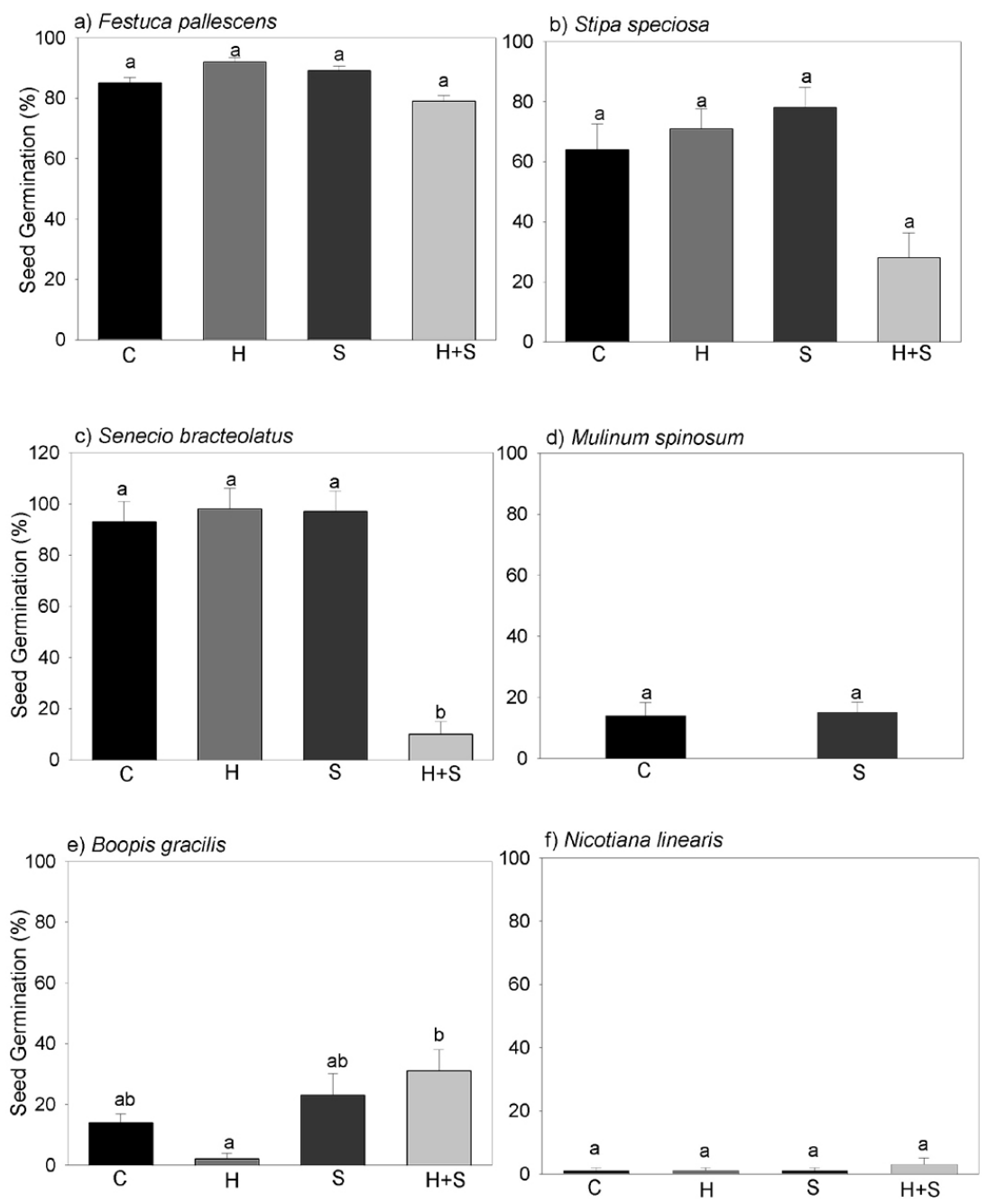

Fig. 1. Mean percentage germination $( \pm \mathrm{SE})$ at Control $(\mathrm{C})$, Heat at $80^{\circ} \mathrm{C}$ for $5 \mathrm{~min}(\mathrm{H})$, Smoke for $60 \mathrm{~min}(\mathrm{~S})$, Heat $+\mathrm{Smoke}(\mathrm{H}+\mathrm{S})$ treatments for the six species (a) Festuca pallescens (b) Stipa speciosa (c) Senecio bracteolatus (d) Mulinum spinosum (e) Boopis gracilis and (f) Nicotiana linearis. Note the change in scale for S. bracteolatus. Different letters indicate significant differences between final germination after 13 weeks of incubation.

and Heat + Smoke treatments (Fig. 1d). Heat-treated Boopis gracilis seeds also had very low germination $(<5 \%)(P<$ $0.05)$. The percentage of germination in Heat + Smoke treatments was two times greater than in Control, although both treatments did not differ significantly (Fig. 1e). Seed germination of Nicotiana linearis was very low $(<3 \%)$ in all treatments (Fig. 1f).

\subsection{Seed viability}

Seed viability in $N$. linearis was not tested because its seeds are very small $(0.65 \times 0.75 \times 0.50 \mathrm{~mm})$ and it was difficult to use the tetrazolium chloride test. However, dissection showed that $N$. linearis seeds had apparently healthy embryos. Every ungerminated seed of $F$. pallescens was dead in all treatments (Fig. 2a). All seeds of S. speciosa, $S$. bracteolatus and $M$. spinosum exposed to Heat + Smoke treatment were dead (Fig. 2b, c and d). The same happened with all ungerminated heat-treated seeds of $M$. spinosum (Fig. 2d). In contrast, a percentage of B. gracilis seeds exposed to Heat and Heat + Smoke treatments were dormant, although in Heat treatment there were more dead seeds than dormant ones $(P<0.05)$ (Fig. 2e).

\section{Discussion}

Fire-related cues affected the seed response of the studied species. There were four main responses linked to fire cues: (a) seeds of the grasses, the shrub Senecio bracteolatus and the fugitive Boopis gracilis tolerated $80^{\circ} \mathrm{C}$. (b) M. spinosum seeds did not tolerate heat shock (c) the seed germination of Stipa speciosa and S. bracteolatus was inhibited by the combined heat and smoke treatment (d) seed germination of 

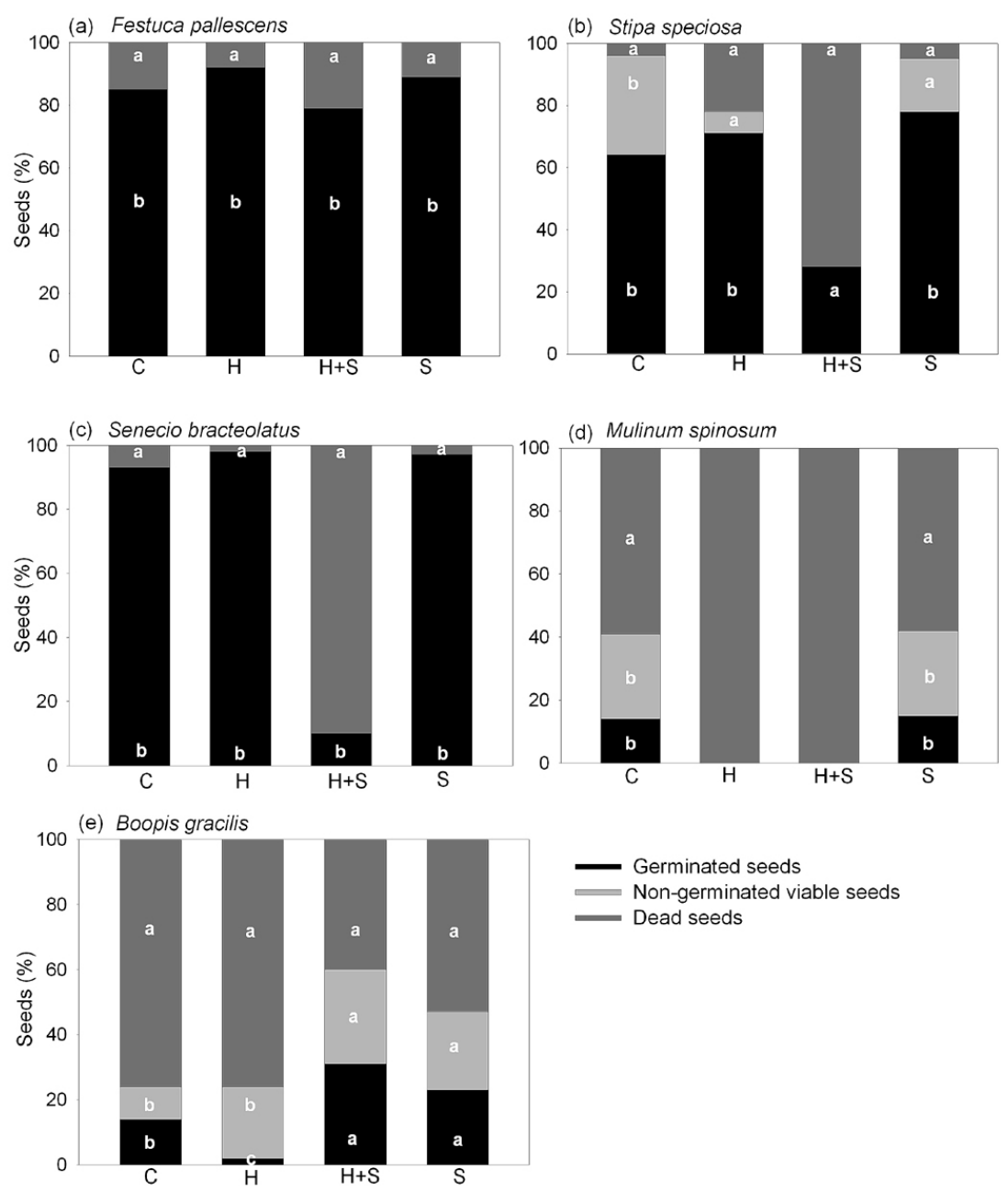

Fig. 2. Percentage of germinated seeds, dormant (ungerminated but viable seeds), and dead seeds according to the tetrazolium chloride test in the treatments: $\mathrm{C}$ (Control), $\mathrm{H}$ (Heat at $80^{\circ} \mathrm{C}$ for $5 \mathrm{~min}$ ), $\mathrm{H}+\mathrm{S}$ (Heat + Smoke), S (Smoke for 60 min) for (a) Festuca pallescens (b) Stipa speciosa (c) Senecio bracteolatus (d) Mulinum spinosum, and (e) Boopis gracilis. Different letters indicate significant differences among condition of the seeds within each treatment.

B. gracilis tended to increase in smoke and heat and smokecombined treatments. Observing the different seed responses of the studied species, we might expect that fire affects the seedling recruitment differentially.

Seed tolerance to high temperatures mainly depends on seed size, the presence of seed protective structures and the hardness and thickness of the seed coat (Herranz et al., 1998; Hanley et al., 2003). In our study, the caryopses of $F$. pallescens and $S$. speciosa grasses tolerated the heat. The structures that cover caryopses (lemmas and paleas) protect the embryo, isolating it from the excessive heat (Gashaw and Michelsen 2002; Williams et al., 2003). Several studies have shown that caryopses of some genera (e.g. Eleusine, Hyparrehnia, Sorghum, Eragrostis, Microlaena and Paspalidium), withstand temperatures higher than those used in the present study $\left(90^{\circ} \mathrm{C}-120^{\circ} \mathrm{C}\right)$ with exposition times that varied from 2 to $30 \mathrm{~min}$ (Gashaw and Michelsen, 2002; Clarke and French, 2005). Moreover, S. speciosa awns are hygroscopically-active and can bury the caryopsis into the soil through a mechanism called drill effect (Ghermandi, 1995). This mechanism anchors the caryopsis in a safe site for successful germination and seedling establishment (Peart and Clifford, 1987). Since buried seeds are more likely to survive fire because soil buffers high surface temperatures (Wright and Bailey, 1982), S. speciosa could increase the postfire survival of caryopses through self burial behaviour.

S. bracteolatus and B. gracilis seeds also tolerated high temperature, but $M$. spinosum seeds were killed by heat. Some authors have found an inverse relationship between seed size and tolerance to heat shock (Hanley and Fenner, 2003; Overbeck et al., 2006). S. bracteolatus $(0.4 \mathrm{mg})$ and $B$. gracilis $(0.8 \mathrm{mg})$ seeds are smaller compared to $M$. spinosum seeds $(4.8 \mathrm{mg})$, supporting this hypothesis. Most likely, the seed size could explain these different responses, although this variable was not tested in this study. 
The combined heat and smoke treatment produced opposite seed germination responses, inhibiting $S$. speciosa and $S$. bracteolatus, and stimulating $B$. gracilis. A similar treatment decreased seed germination of two Australian legumes (Williams et al., 2003). Apparently, there is a saturation point and possibly a smoke exposure threshold, above which germination begins to decline or even may be inhibited (Willis et al., 2003). The mechanisms that provoked these responses are not known, but it is possible that heat scarifies seeds and allows faster smoke entry. Smoke at high concentrations or for long periods of exposure can be toxic (Dixon et al., 1995; Baldwin et al., 1994). As an example of this, more than $60 \mathrm{~min}$ of smoke application directly onto seeds inhibited the seed germination of Australian species (Roche et al., 1997). In contrast, combined heat and smoke increased the germination of $B$. gracilis seeds, although the exposition to heat inhibited it. Studies of fugitive species which have assessed the combined influences of fire cues on seed germination reported variable results. Seeds of Actinotus leucocephalus and Codonocarpus cotinifolius ephemeral Australian species increased their germination with heat and smoke, but other species (e.g. Crotalaria montana) responded negatively to this fire factors (Williams et al., 2003; Baker et al., 2005). Temperature can influence physiological processes in the embryo (Bell and Williams, 1998), inducing non-dormant seeds to become dormant again (Baskin and Baskin, 2004). Apparently heat could induce secondary dormancy in $B$. gracilis seeds whereas the presence of smoke could reverse this situation, enhancing seed germination. Thus, the heat produced during fires could delay seed germination until the next spring. The active component of smoke is stored for a long time when attached to soil particles or seed coats (van Staden et al., 2000) and can penetrate the soil when transported by rain, becoming available to buried seeds. Soil-stored seeds may respond to such sequence of stimuli to ensure suitable conditions for seed survival and successful seedling establishment.

Our experimental results did not explain the massive postfire seedling recruitment observed of fugitive species in the field (Ghermandi et al., 2004). Probably, seed germination of the studied species is widely stimulated by other levels and periods of exposure to temperature and smoke, which were not tested in this study. During a fire, seeds can be exposed to a wide range of temperatures and times because these factors are very heterogeneous (Tsuyusaki and Miyoshi, 2009). Moreover, likely direct fire cues are not a sufficient stimulus for the dormant fraction of seeds, thus other cues may be necessary. The removal of biomass and litter by fires became the postfire environment into the "big gap" (Gonzalez and Ghermandi, 2008), where space and resources such as light and temperature fluctuation increase and the competition is reduced (Bond and van Wilgen, 1996). Moreover, since in general species of the genus Nicotiana have physiological dormancy, their seeds probably require the occurrence of dormancy-breaking factors like stratification in order to germinate (Finch-Savage and Leubner-Mezger, 2006). Direct and indirect fire cues could account for the abundance of seedlings of fugitive species observed after wildfires and after experimental fires. However, more studies are needed to test these hypotheses as well as the requirements to break seed dormancy.

In conclusion, seed tolerance to heat shock of the grasses and S. bracteolatus is ecologically relevant because it could increase their survival during fires and probably the recruitment of new seedlings in the postfire environment. Moreover, the increase in seed germination of the fugitive $B$. gracilis when exposed to smoke and to the combination of heat and smoke, is a signal of adaptation to fire (sensu Hopper, 2003). This behaviour indicates the evolution of this species in environments subjected to frequent fires. These species are not only directly affected by fire, but can also benefit from other postfire gap-related cues, such as temperature and light fluctuations and the reduction of competition. The brief temporary presence of the fugitive species in the vegetation causes important changes in the early postfire community, such as increase in diversity and species' richness (Gonzalez and Ghermandi, 2008). Finally, the seedling recruitment in these grasslands could be affected by other factors like the competition and facilitation with other plants, the availability of safe sites (Franzese et al., 2009; Gonzalez et al., 2010), and fire, as shown in the present study. This implies that a change in the future fire regime could affect the composition and abundance of typical species of the northwestern Patagonian grasslands.

Acknowledgements. This work was supported by the Universidad Nacional del Comahue (Project B-131) and the Consejo Nacional de Investigaciones Científicas y Técnicas. We thank Jorgelina Franzese for her assistance in laboratory work, Pablo Parodi for his help in construction of the "smoke device", and Charlotte Reemts, Natalie Dudinszky and Jorgelina Franzese for their help in the English revision. We also extend our thanks to San Ramón, ranch manager.

Edited by: R. Lasaponara

Reviewed by: A. Lanorte and two anonymous referees

\section{References}

Baker, K. S., Steadman, K. J., Plummer, J. A., Merritt, D. J., and Dixon, K. W.: The changing window of conditions that promotes germination of two fire ephemerals, Actinotus leucocephalus (Apiaceae) and Tersonia cyathiflora (Gyrostemonaceae), Annals of Botany, 96, 1225-1236, 2005.

Baldwin, I. T., Staszak-Kozinski, L., and Davidson, R.: Up in smoke: I smoke-derived germination cues for postfire annual, Nicotiana attenuata torr. Ex. Watson, J. Chem. Ecol,, 20, 23452371, 1994.

Baskin, C. C. and Baskin, J. M.: Seed ecology, biogeography and evolution of dormancy and germination, Academic Press, San Diego, 1998. 
Baskin, J. M. and Baskin, C. C.: A classification system for seed dormancy, Seed Sci. Res., 14, 1-16, 2004.

Bell, D. T. and Williams, D. S.: Tolerance of thermal shock in seeds, Aust. J. Bot., 46, 221-233, 1998.

Boelcke, O.: Comunidades herbáceas del Norte de la Patagonia y sus relaciones con la ganadería, Revista de Investigaciones Agropecuarias, 6, 5-98, 1957 (in Spanish).

Bond, W. J. and van Wilgen, B. W.: Fire and plants, Chapman \& Hall, London, 1996.

Clarke, S. and French, K.: Germination response to heat and smoke of 22 Poaceae species from grassy woodlands, Aust. J. Bot., 53, 445-454, 2005.

de Torres Curth, M. I., Ghermandi, L., and Pfister, G.: Los incendios en el noroeste de la Patagonia: su relación con las condiciones meteorológicas y la presión antrópica a lo largo de 20 años, Ecol. Austral, 18, 153-167, 2008 (in Spanish).

Dixon, K., Roche, S., and Pate, J.: The promotive effect of smoke derived from burnt native vegetation on seed germination of Western Australian plants, Oecologia, 101, 185-192, 1995.

Finch-Savage, W. E. and Leubner-Metzger, G.: Seed dormancy and the control of germination, New Phytol., 171, 501-523, 2006.

Franzese, J. and Ghermandi, L.: Seed longevity and fire: germination responses of an exotic perennial herb in NW Patagonian grasslands (Argentina), Plant Biol., in press, 2011.

Franzese, J., Ghermandi, L., and Bran, D.: Postfire shrub recruitment in a semi-arid grassland: the role of microsites, J. Veg. Sci., 20, 251-259, 2009.

Gashaw, M. and Michelsen, A.: Influence of heat shock on seed germination of plants from regularly burnt savanna woodlands and grasslands in Ethiopia, Vegetatio, 159, 83-93, 2002.

Ghermandi, L.: The effect of the awn on the burial and germination of Stipa speciosa (Poaceae), Acta Oecol., 16, 719-728, 1995.

Ghermandi, L., Guthmann, N., and Bran, D.: Early post-fire succession in northwestern Patagonia grasslands, J. Veg. Sci., 15, 67-76, 2004.

Gilmour, C. A., Crowden, R. K., and Koutoulis, A.: Heat shock, smoke and darkness: partner cues in promoting seed germination in Epacris tasmanica (Epacridaceae), Aust. J. Bot., 48, 603-609, 2000.

Gonzalez, S. and Ghermandi, L.: Postfire seed bank dynamics on semiarid grasslands, Plant Ecol., 199, 175-185, 2008.

Gonzalez, S., Franzese, J., and Ghermandi L.: Role of fire on Patagonian grasslands: changes in aboveground vegetation and soil seed bank, in: Advances in Environmental research, Volume 2, edited by: Haider, M. and Müller, T., Nova Publishers, USA, 2010.

Hanley, M. E., Unna, J. E., and Darwill, B.: Seed size and germination response: a relationship for fire-following plant species exposed to thermal shock, Oecologia, 134, 18-22, 2003.

Herranz, J. M., Ferrandis, P., and Martínez-Sánchez, J. J.: Influence of heat on seed germination of seven Mediterranean Leguminosae species, Plant Ecol., 136, 95-103, 1998.

Hopper, S. D.: An evolutionary perspective on south-west Western Australian landscapes, biodiversity and fire: a review and management implications, in: Fire in ecosystems of south-west Western Australia: impacts and management, edited by: Abbott, I. and Burrows, N., Backhuys Publishers, Leiden, 2003.
Keeley, J. E. and Fotheringham, C. J.: Mechanism of smokeinduced seed germination in a post-fire chaparral annual, J. Ecol., 86, 27-36, 1998.

Keeley, J. E. and Fotheringham, C. J.: Role of fire in regeneration from seed, in: Seeds: the ecology of regeneration in plant communities, edited by: Fenner, M., CAB International, Oxon, UK, 2000.

Keeley, J. E., McGinnis, T. W., and Bollens, K..: Seed germination of Sierra Nevada postfire chaparral species, Madroño, 52, 175181, 2005.

Morris, E. C.: Germination response of seven east Australian Grevillea species (Proteaceae) to smoke, heat exposure and scarification, Aust. J. Bot., 48, 179-189, 2000.

Overbeck, G. E., Müller, S. C., Pillar, V. D., and Pfadenhauer, P.: No heat-stimulated germination found in herbaceous species from burned subtropical grassland, Plant Ecol., 184, 237-243, 2006.

Peart, M. H. and Clifford, H. T.: The influence of diaspore morphology and soil-surface properties on the distribution of grasses, J. Ecol., 75, 569-576, 1987.

Pennacchio, M., Jefferson, L., and Havens, K.: Allelopathic effects of plant-derived aerosol smoke on seed germination of Arabidopsis thaliana(L.) Heynh., Research Letters in Ecology, 1-4, 2007.

Roche, S., Koch, J. M., and Dixon, K. W.: Smoke enhanced seed germination for mine rehabilitation in the Southwest of Western Australia, Restor. Ecol., 5, 191-203, 1997.

Thomas, P. B., Morris, C., and Auld, T.: Response surfaces for the combined effects of heat shock and smoke on germination of 16 species forming soil seed banks in south-east Australia, Austral Ecol., 32, 605-616, 2007.

Tsuyusaki, S. and Miyoshi, C.: Effects of smoke, heat, darkness and cold stratification on seed germination of 40 species in a cool temperate zone in northern Japan, Plant Biol., 11, 369-378, 2009.

Valbuena, L. and Vera, M. L.: The effects of thermal scarification and seed storage on germination of four heathland species, Plant Ecol., 161, 137-144, 2002.

van Staden, J., Brown, N. A. C., Jäger, A. K., and Johnson, T. A.: Smoke as a germination cue, Plant Spec. Biol., 5, 167-178, 2000.

Whelan, R. J.: The ecology of fire, Cambridge University Press, Melbourne, 1995.

Williams, P. R., Congdon, R. A., Grice, A. C., and Clarke, P. J.: Fire-related cues break seed dormancy of six legumes of tropical eucalypt savannas in north-eastern Australia, Austral Ecol., 28, 507-504, 2003.

Willis, A. J., McKay, R.,Vranjic, J. A., Kilby, M. J., and Groves, R. H.: Comparation seed ecology of the endangered shrub Pimelea spicata and the threatening weed, Bridal creeper: Smoke, heat and other fire-related germination cues, Ecological Management \& Restoration, 4, 55-65, 2003.

Wright, H. A. and Bailey, A. W.: Fire Ecology, John Wiley and Sons, New York, USA, 1982. 